\title{
Increases in Extracellular Dopamine in the Nucleus Accumbens by Cocaine Are Inversely Related to Basal Levels: Effects of Acute and Repeated Administration
}

\author{
Friedbert Weiss, ${ }^{1}$ Martin P. Paulus, ${ }^{2}$ Marge T. Lorang, ${ }^{1}$ and George F. Koob ${ }^{1}$ \\ 'Department of Neuropharmacology, The Scripps Research Institute, La Jolla, California 92037 and 'Department of \\ Psychiatry, University of California at San Diego, La Jolla, California 92039
}

Repeated administration of cocaine enhances several of the behavioral and neurochemical responses to subsequent cocaine injections, an effect that has been attributed, in part, to decreased somatodendritic autoreceptor sensitivity of mesocorticolimbic dopamine (DA) neurons. Such changes in autoregulation may not only modify the direct effects of cocaine on extracellular DA levels but also result in tonically increased basal DA release in the terminal areas of the mesocorticolimbic DA system. The present study was therefore designed to investigate the effects of repeated cocaine administration on basal extracellular DA concentrations in the nucleus accumbens (NAC) using in vivo microdialysis procedures in halothane-anesthetized rats. We subsequently examined the relationship between basal DA levels and the increase in extracellular DA produced by an acute injection of cocaine, and determined whether this relationship was altered by prior, repeated exposure to cocaine. Rats received one daily intraperitoneal injection of cocaine (30 $\mathbf{~ m g}$ / $\mathbf{k g}$ ) or its vehicle (saline) for 10 consecutive days. On days 1,3 , or 7 after termination of the repeated cocaine treatment, extracellular DA levels in the NAC were determined under basal conditions and following a single intraperitoneal cocaine challenge injection $(10 \mathrm{mg} / \mathrm{kg}$ ) in separate groups of rats. Repeated cocaine administration produced a substantial increase in basal DA release in the NAC that was most prominent on day 1 post-cocaine (mean \pm SEM: $10.7 \pm 2.55$ $\mathrm{nM}$ vs $3.55 \pm 0.56 \mathrm{~nm}$ ) but was no longer apparent on day 7 post-cocaine. Higher extracellular DA levels were also observed after cocaine challenge in rats that received repeated cocaine treatments. Similar to the increase in basal release, this effect was most pronounced on day 1 post-cocaine (23.6 $\pm 4.36 \mathrm{~nm}$ vs $12.61 \pm 1.76 \mathrm{~nm}$ ) but did not persist through day 7 post-cocaine. In spite of higher absolute DA concentrations in repeated-cocaine-treated rats, the relative increase in DA over basal levels after cocaine challenge was considerably smaller in this group $(252 \pm 39 \%)$ than in repeated-saline-treated control animals (412 $\pm 49 \%)$. Further

Received Mar. 24, 1992; revised June 2, 1992; accepted June 9, 1992.

This is publication 7242NP from The Scripps Research Institute. We thank Drs. Floyd Bloom and Steve Henriksen for critical comments on an early draft of the manuscript and express our gratitude to Dr. John Polich for statistical assistance. This work was supported in part by Grants DA 05843 and DA 04398 from the National Institute on Drug Abuse.

Correspondence should be addressed to Friedbert Weiss, Department of Neuropharmacology (CVN-15), The Scripps Research Institute, 10666 North Torrey Pines Road, La Jolla, CA 92037.

Copyright (C) 1992 Society for Neuroscience $0270-6474 / 92 / 124372-09 \$ 05.00 / 0$ analysis of the relationship between basal and maximal DA levels after cocaine challenge revealed a dependence of cocaine effects on basal DA levels such that the efficacy of cocaine to produce increases in DA overflow was progressively reduced with increasing basal levels. This relationship was not changed by repeated cocaine pretreatments. The results demonstrate that some form of functional tolerance to the effects of cocaine can develop in spite of marked elevations in absolute extracellular DA concentrations and suggest that the extracellular dopaminergic response to cocaine in the NAC is reduced in animals with higher levels of basal DA release.

The growing problem of cocaine abuse and abuse-related health problems has stimulated considerable research in an effort to understand the physiological bases of cocaine abuse and dependence. An increasing number of neurochemical, physiological, and behavioral data now indicate that repeated or chronic cocaine administration can produce profound changes in mesocorticolimbic dopaminergic function at multiple synaptic levels. Repeated administration of cocaine enhances stimulated dopamine (DA) release and uptake and augments the effects of cocaine challenge injections on extracellular DA levels in the nucleus accumbens (NAC; Kalivas and Duffy, 1990; Pettit et al., 1990; Ng et al., 1991), increases mesolimbic DA neuronal activity (Henry et al., 1989), decreases DA synthesis (Taylor and Ho, 1977; Nielsen et al., 1983; Brock et al., 1990; BeitnerJohnson and Nestler, 1991), and changes DA receptor sensitivity at both the pre- and postsynaptic level (Roy et al., 1978; Goeders and Kuhar, 1987; Trulson and Ulissey, 1987; Dwoskin et al., 1988; Yi and Johnson, 1990). Behavioral effects of repeated cocaine treatments are often characterized by a progressive and potent enhancement (i.e., sensitization) of locomotor and stereotyped behavior produced by the same dose of cocaine (e.g., Roy et al., 1978; Kalivas et al., 1988; Post and Weiss, 1988; Kalivas and Duffy, 1990). Sensitization may also develop to the reinforcing and discriminative stimulus properties of cocaine (Lett, 1989; Horger et al., 1990). However, the latter effects appear less pervasive and remain controversial because repeated administration has also been demonstrated to diminish the efficacy of cocaine as a discriminative stimulus and to induce tolerance to the subjective and reinforcing effects of this drug (Fishman et al., 1985; Wood and Emmett-Oglesby, 1986; Emmett-Oglesby and Lane, 1992).

Considerable evidence implicates the mesocorticolimbic DA system in the mediation of the acute reinforcing effects of co- 
caine self-administration as well as in its motor stimulant effects (Kelly et al., 1976; DeWit and Wise, 1977; Roberts et al., 1977; Roberts and Koob, 1982; Koob et al., 1987). Withdrawal from cocaine after periods of unlimited access is associated with decreased basal DA release (Weiss et al., 1992a,b) and attenuation of brain stimulation reward (Kokkinidis and McCarter, 1990; Markou and Koob, 1991). These demonstrations suggest that DA neurotransmission in the NAC may also be critically involved in cocaine dependence and possibly the anhedonic effects of cocaine withdrawal. Therefore, chronic cocaine-induced changes in mesocorticolimbic DA function may play an important role in motivational processes related to cocaine-seeking behaviors including the development of dependence, cocaine "craving," and possibly in the pathological side effects associated with chronic cocaine abuse.

Recent electrophysiological findings indicate that, similar to previous observations with $d$-amphetamine (White and Wang, 1984), repeated cocaine administration weakens the suppressive effects of apomorphine on A10 DA neuronal activity presumably due to a subsensitivity of somatodendritic DA autoreceptors (Henry et al., 1989; Ackerman and White, 1990). Somatodendritic autoreceptor subsensitivity has also been implicated in the attenuation of amphetamine-stimulated DA release in the ventromedial mesencephalon of "cocaine-sensitized" rats (Kalivas et al., 1988). These findings suggest that subsensitivity of somatodendritic DA autoreceptors after repeated cocaine administration may result in tonically increased basal DA release in the terminal regions of the mesocorticolimbic DA system, particularly in the NAC. Consistent with this possibility, increased levels of basal DA release have recently been observed in the NAC of rats following a 2 week period of daily, limitedaccess cocaine self-administration (Weiss et al., 1992b). Such systematic changes in basal DA release would be an important neurochemical correlate of chronic cocaine exposure and may be particularly important for the interpretation of the effects of chronic cocaine treatments with regard to the development of pharmacological sensitization or tolerance.

The present experiments were designed to characterize further the relationship of basal DA activity to drug-stimulated increases in extracellular DA concentrations by (1) investigating the effects of repeated cocaine administration on basal DA release in the rat NAC, (2) examining whether a functional relationship exists between basal DA release and the peak increase in extracellular DA levels after an acute injection of cocaine, and (3) detcrmining whether this relationship is altered by repeated cocaine pretreatment. The time course and persistence of the effects of repeated cocaine exposure were examined by testing animals on days 1, 3, and 7 after termination of the repeated cocaine pretreatment.

\section{Materials and Methods}

Subjects. Fifty-eight male Wistar rats (Charles River Co.) weighing between $300-400 \mathrm{gm}$ at the time of testing were used in all experiments. The rats were housed in groups of three in a humidity- and temperature $\left(22^{\circ} \mathrm{C}\right.$ )-controlled vivarium on a $12 \mathrm{hr}: 12 \mathrm{hr}$ light/dark cycle (on, 05: 00; off, 17:00) with ad libitum access to food and water.

Intracranial microdialysis. Microdialysis was performed under general anesthesia induced by a halothane (3\%)-oxygen (95\%) mixture and maintained by $0.8-1.2 \%$ halothane. Body temperature was maintained at $37.5^{\circ} \mathrm{C}$ by a small animal temperature control system [CMA/160, Bioanalytical Systems, Lafayette, IN (BAS)]. Microdialysis probes (CMA/ 10 , BAS) with $2 \mathrm{~mm}$ membrane tips and an outer diameter of $500 \mu \mathrm{m}$ werc stcrcotaxically (David Kopf Instruments, Tujunga, CA) lowered unilaterally toward the ventral border of the NAC. With reference to bregma, the coordinates defining the location of the distal end of the membrane were A 1.7, M 1.5, and V 8.0 according to the atlas of Paxinos and Watson (1986). The microdialysis probes were continuously perfused with Ringer's solution at a rate of $2 \mu \mathrm{l} / \mathrm{min}$. Sampling began $1 \mathrm{hr}$ after probe insertion. Perfusate fractions were collected at $10 \mathrm{~min}$ intervals into microfraction vials containing $2 \mu \mathrm{l}$ of $0.1 \mathrm{~m}$ perchloric acid. The samples were assayed immediately for DA content. Once stable basal DA levels were noted over three consecutive fractions $( \pm 10 \%)$, rats received one single intraperitoneal injection of cocaine. After cocaine challenge injections, sampling continued at $10 \mathrm{~min}$ intervals for an additional $60 \mathrm{~min}$. The in vitro recovery of microdialysis probes was determined prior to each experiment. The mean recovery value across all probes was subsequently used to standardize dialysate neurotransmitter concentrations. This was accomplished by multiplying sample DA concentrations $\left(C_{\text {Samplc }}\right)$ by the ratio of mean recovery $\left(\operatorname{Rec}_{\text {Mean }}\right)$ to individual probe ( $\mathrm{Rec}_{\text {Ind }}$ ) recovery: standardized dialysate concentration $=\left(\operatorname{Rec}_{\mathrm{Mcan}} / \operatorname{Rec}_{\text {lnd }}\right) \times C_{\text {Sample. }}$. The mean $( \pm \mathrm{SEM})$ in vitro recovery for DA was $10.99 \pm 0.38 \%$

Analytical procedures. Dopamine dialysate concentrations were determined by reverse-phase HPLC coupled with electrochemical detection. Collected dialysate fractions were transferred to a refrigerated $\left(4^{\circ} \mathrm{C}\right)$ autoinjector (CMA 200, BAS) programmed to inject $10 \mu$ ldialysate aliquots onto a $5 \mu \mathrm{m}$ ODS column $(2.1 \mathrm{~mm} \times 100 \mathrm{~mm}$; Spherisorb, Brown-Lee Laboratories, Santa Clara, $\mathrm{CA}$ ). The mobile phase consisted of a $0.1 \mathrm{M}$ sodium phosphate (monobasic) buffer containing $0.1 \mathrm{M}$ acetic acid, $1.7 \mathrm{~mm}$ sodium octyl sulfate as an ion-pairing reagent, $0.3 \mathrm{~mm}$ EDTA, $6.7 \%$ acetonitrile, and 1.3\% tetrahydrofuran ( $\mathrm{pH} 4.0$ before addition of organic modifiers). The flow rate of the mobile phase was $200 \mu \mathrm{l} / \mathrm{min}$ delivered by an isocratic HPLC pump (Isochrom, Spectraphysics, San Jose, CA). Dopamine was detected on a glassy-carbon working electrode (BAS) controlled by an EG\&G Princeton Applied Research (model 400 ) electrochemical detector. The applied potential was $700 \mathrm{mV}$ (vs $\mathrm{Ag} / \mathrm{AgCl}$ ). Chromatograms were recorded and quantified by a Hewlett-Packard (HP 3394A) integrator. Sample peaks were identified and quantified by relating retention times and peak heights to those of an external calibrating standard solution.

Histology. Microdialysis sites were histologically examined after completion of the microdialysis experiments in a sample of $70 \%$ of all animals. Rats were killed by an overdose of halothane $(5 \%)$, and brains were removed and stored in formalin. Probe placements within the NAC were subsequently confirmed from $50 \mu m$ frozen, cresyl violel-stained sections. In all examined cases, at least $80 \%$ of the active portion of the dialysis membrane was located within the NAC.

Experimental design. Rats were pretreated with one daily intraperitoneal injection of cocaine hydrochloride $(30 \mathrm{mg} / \mathrm{kg}$ ) or its vehicle (saline, $1 \mathrm{ml} / \mathrm{kg}$ ) for 10 consecutive days. All daily injections were administered at 1:00 P.M. Upon completion of the pretreatment, basal DA output and extracellular levels of DA in the nucleus accumbens after a cocaine challenge injection $(10 \mathrm{mg} / \mathrm{kg}$, i.p.) were determined by intracranial microdialysis under halothane anesthesia. The tests were conducted on day 1 ( $24 \mathrm{hr}$ ), day 3 , and day 7 after the final daily cocaine injection in separate groups of rats. The daily cocaine dose of $30 \mathrm{mg} /$ $\mathrm{kg}$ was chosen to approximate self-administered doses of about $30 \mathrm{mg} /$ $\mathrm{kg} / 3 \mathrm{hr}$, which were shown previously to produce marked alterations in extracellular DA levels (Weiss et al., 1992a). A challenge dose of 10 $\mathrm{mg} / \mathrm{kg}$ was selected because of earlier observations in which $30 \mathrm{mg} / \mathrm{kg}$ doses proved lethal in combination with halothane anesthesia in $30 \%$ of saline-pretreated (i.e., non-cocaine-acclimated) rats. To control for the effects of differing daily and challenge doses, an additional group of rats were pretreated and tested with a $10 \mathrm{mg} / \mathrm{kg}$ dose of cocaine. These animals were tested $24 \mathrm{hr}$ (day 1) after the daily pretreatment only.

Data analysis. Basal DA concentrations and cocaine challenge data were analyzed by $3 \times 4 \times 4$ and $3 \times 2 \times 7$ (test day $\times$ repeated treatment $\times$ sampling interval) mixed factorial analyses of variance (ANOVAs), respectively, where "sampling interval" represents the only within-subjects (repeated) variable. Data of animals pretreated with the lower $10 \mathrm{mg} / \mathrm{kg}$ cocaine dose were analyzed by $2 \times 4$ (basal) and $2 \times$ 7 (cocaine challenge; repeated treatment $\times$ sampling interval) mixed factorial ANOVAs. Following confirmation of significant effects by the overall ANOVAs, differences between repeated-cocaine groups tested on days 1,3 , or 7 and the pooled repeated-saline control groups were identified by $2 \times 4$ (basal) and $2 \times 7$ (cocaine challenge) ANOVAs. Differences among means of saline- or cocaine-pretreated animals at individual sampling intervals were subscquently determincd by analyses of simple effects. The relationship between basal and peak DA concen- 


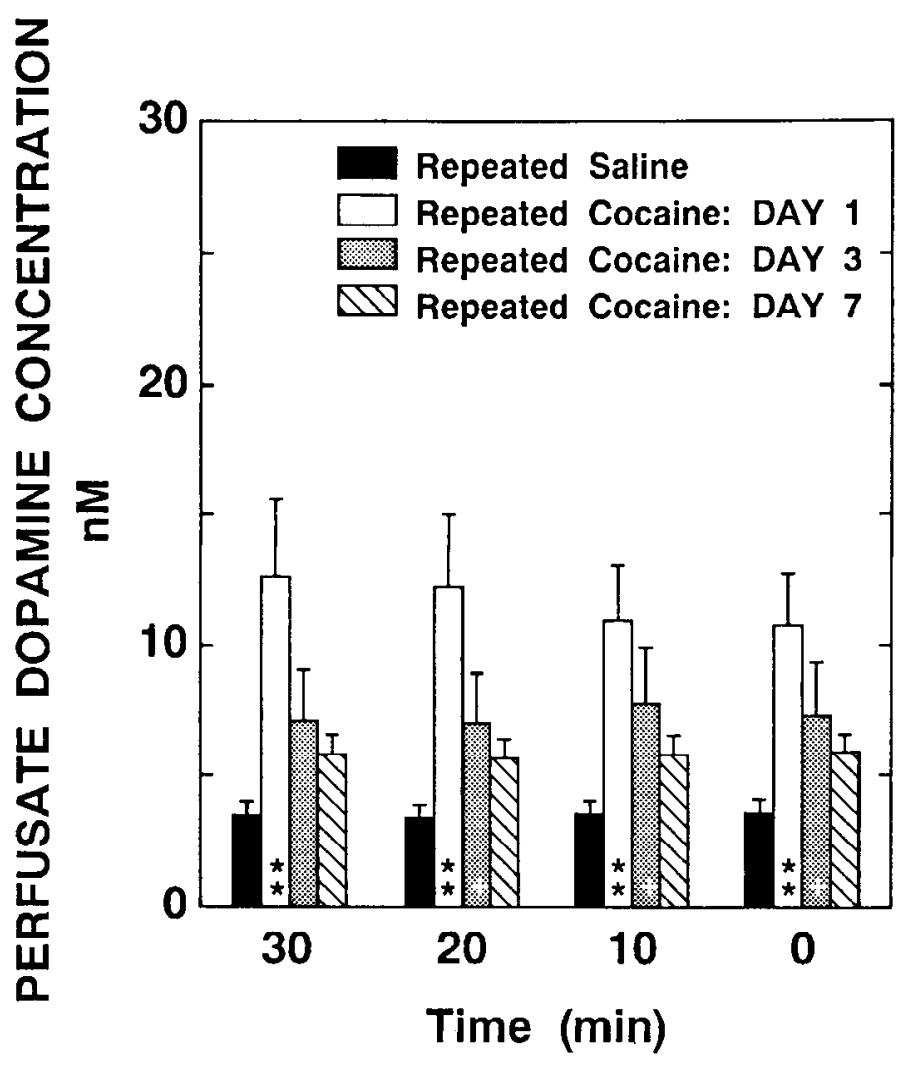

Figure 1. Basal DA levels in microdialysates collected from the NAC of repeated-cocaine- or saline-pretreated rats. Ten days of repeated cocaine administration substantially increased basal DA overflow. This effect was most pronounced on $D A Y I(n=13)$ and decreased progressively with time. Moderate increases were still evident on postcocaine $D A Y 3(n=12)$ but not on $D A Y 7$ post-cocaine $7(n=10)$. Data of the repeated-cocaine-treated groups are compared to the pooled data of all repeated-saline-treated control rats. ${ }^{* *}, p<0.005 ;+, 0.1>$ $p>0.05$ (simple effects after ANOVA).

trations after cocaine challenge injections was examined by first-order regression analyses on logarithmically (In) transformed data. The linearity of this relationship was rejected if the $95 \%$ confidence interval of the slope of the regression line did not include 1.0.

\section{Results}

Effects of repeated cocaine administration on basal $D A$ release. Daily cocaine administration $(30 \mathrm{mg} / \mathrm{kg}$ ) produced substantial elevations in basal dialysate DA concentrations. The increase in basal DA overflow was most pronounced on post-cocaine day 1 and decreased progressively with time (Fig. 1). The existence of statistically reliable increases in basal DA levels of repeated-cocaine- over repeated-saline-treated rats was confirmed by the overall ANOVA $(F=5.23$; $\mathrm{df}=1 / 46 ; p<0.05)$. No difference in basal DA overflow was detected among repcated-saline-treated rats tested on days 1,3 , and 7 ( $F=0.89$; df $=2 / 11$; NS). The basal DA values of these animals were therefore pooled for subsequent comparisons with the repeatedcocaine data of days 1,3 , and 7 . These analyses confirmed significant differences in basal DA levels of cocaine-pretreated groups from the pooled, daily-saline-treated groups on day 1 ( $F$ $=9.93 ; \mathrm{df}=1 / 25 ; p<0.005)$. Marginal differences were still evident on day $3(F=3.39 ; \mathrm{df}=1 / 24 ; 0.1>p>0.05)$, but not on day 7 ( $F=2.67$; $\mathrm{df}=1 / 25$; NS).

Effects of cocaine challenge injections on DA overflow. Cocaine challenge injections $(10 \mathrm{mg} / \mathrm{kg})$ produced strong increases in perfusate DA concentrations in both daily-saline- and cocaine $(30 \mathrm{mg} / \mathrm{kg})$-pretreated rats on each $(p<0.0001)$ of the three post-cocaine test days (simple effects after ANOVA: $F=38.07$; $\left.\mathrm{d} \int=6 / 276 ; p<0.0001\right)$. However, there were marked, statistically reliable differences in cocaine effects as a function of pretreatment conditions and the number of days elapsed since the termination of the daily cocaine treatment. Perfusate DA concentrations reached significantly higher levels in repeatedcocaine-injected rats after challenge injections, than in salinetreated rats $(F=5.07 ; \mathrm{df}=1 / 46 ; p<0.05$; Fig. 2$)$. No differences in the effects of cocaine challenge injections were apparent among the repeated-saline-treatment groups $(F=0.19 ; \mathrm{df}=2 / 11$; NS). Therefore, the pooled data of these animals were used for all subsequent analyses. Like the increases in basal DA levels above, the enhanced DA overflow in the repeated-cocaine group after cocaine challenge was strongest on day 1 and decreased over time on day 3 and day 7 post-cocaine. Statistical analysis confirmed significant differences from repeated-saline-treated animals on day $1(F=7.81 ; \mathrm{df}=1 / 25 ; p<0.01)$ and day $3(F=$ $4.48 ; \mathrm{d} \Gamma=1 / 24 ; p<0.05)$, but not on day $7(F=1.55 ; \mathrm{d} \Gamma=1 /$ 25 ; NS). The results also revealed a more rapid rate of disappearance in extracellular DA after repeated cocaine treatment as indicated by the steeper descending limbs of the DA response profiles to cocaine challenge. This effect was confirmed by statistically significant interactions on day $1(F=2.37 ; \mathrm{df}=6 / 150$; $p<0.05)$ and day $3(F=2.76 ; \mathrm{df}=6 / 144 ; p<0.05)$.

To compensate for the systematic differences in basal DA overflow between the daily saline and cocaine groups, increases in perfusate $\mathrm{D} \Lambda$ concentrations after cocaine challenge were also examined relative to their corresponding basal values. These analyses revealed that the relative (percentage of basal) increase in perfusate DA levels were considerably smaller in repeatedcocaine- as opposed to repeated-saline-treated rats $(F=4.60$; df $=1 / 46 ; p<0.05)$. On challenge day 1 , cocaine injections produced a mean $( \pm$ SEM) peak increase to $412 \%( \pm 49 \%)$ of basal DA levels in the repeated-saline group. In contrast, the corresponding increase in repeated-cocaine-treated rats was only $252 \%( \pm 39 \%)$. The acute-repeated differences were most prominent on day $1(F=9.49 ; \mathrm{df}=1 / 25 ; p<0.05)$. While reductions in the percentage of basal increases in daily-cocaine-treated rats were still evident on challenge days $3(F=0.55 ; \mathrm{df}=1 / 24 ; \mathrm{NS})$ and $7(F=2.75 ; \mathrm{df}=1 / 25 ; \mathrm{NS})$, this effect was not statistically reliable (Fig. 2). In addition, a significant interaction between pretreatment and sampling intervals on challenge day $1(F=$ 9.49; $\mathrm{df}=1 / 25 ; p<0.05$ ) indicated that when standardized on the basis of basal values, the dopaminergic response to cocaine challenge was "blunted" in the repeated-cocaine group, with a somewhat slower rate of decline in DA levels relative to the repeated-saline group.

Pretreatment for $10 \mathrm{~d}$ with the lower $(10 \mathrm{mg} / \mathrm{kg})$ daily cocaine dose produced the same pattern of results as the $30 \mathrm{mg} / \mathrm{kg}$ repeated dose. A marked enhancement in basal DA overflow was evident on day $1(F=43.92 ; \mathrm{df}=1 / 18 ; p<0.001$; Fig. $3 A)$. Extracellular DA levels after cocaine challenge injections (10 $\mathrm{mg} / \mathrm{kg}$ ) were significantly higher in rats given repeated cocaine than in saline-pretreated rats $(F=37.09 ; \mathrm{df}=1 / 18 ; p<0.001$ Fig. $3 B$ ). As observed above, when examined relative to basal values, the increase in DA levels produced by cocaine challenge injections on day 1 was substantially smaller in repeated-cocaine- than in repeated-saline-pretreated animals $(F=20.37$; $\mathrm{df}=1 / 18 ; p<0.01$; Fig. $3 C$ ). Interaction effects between pretreatment and sampling intervals were also consistent with those 

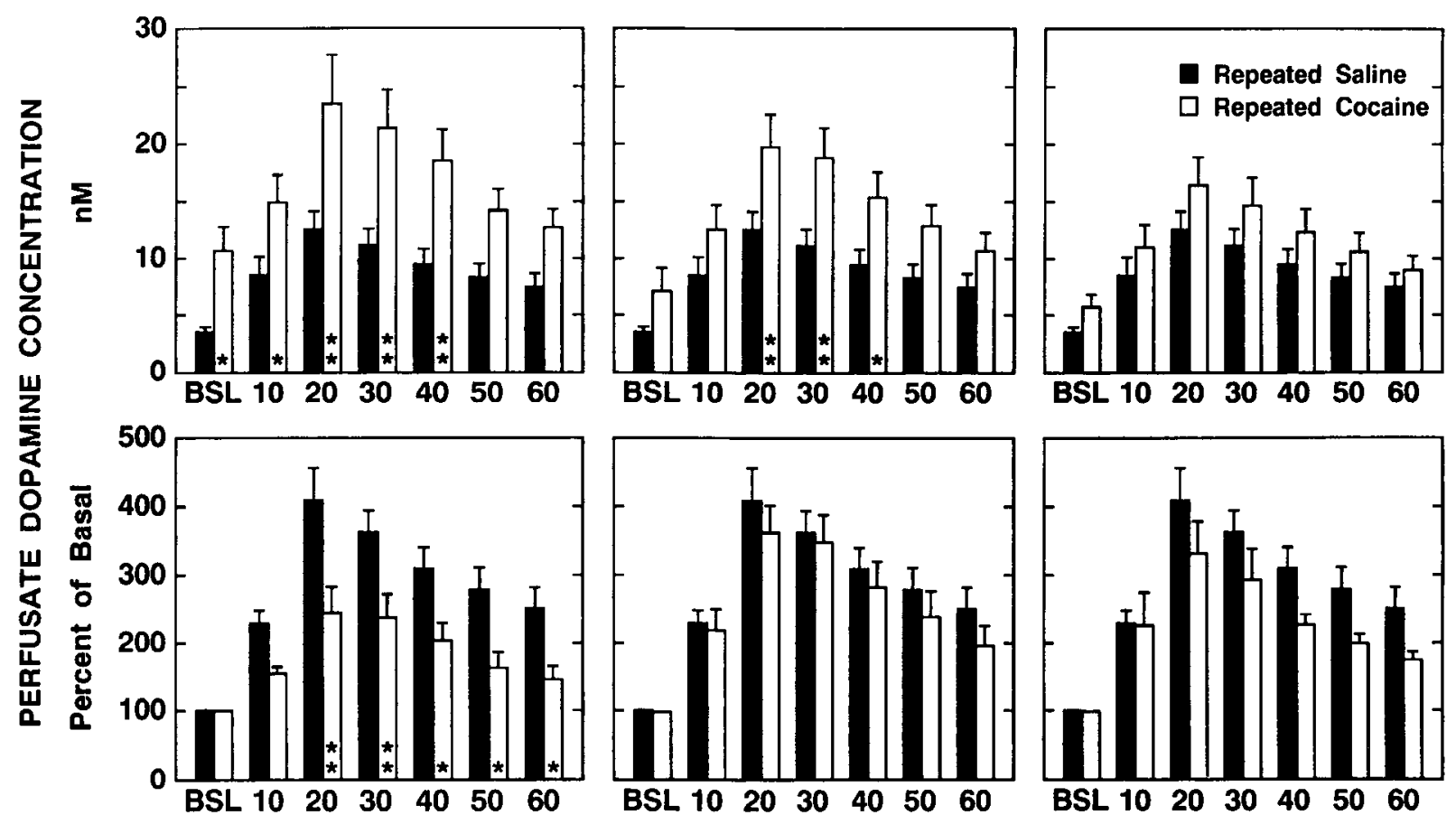

\section{DAY 1 Post-Cocaine}

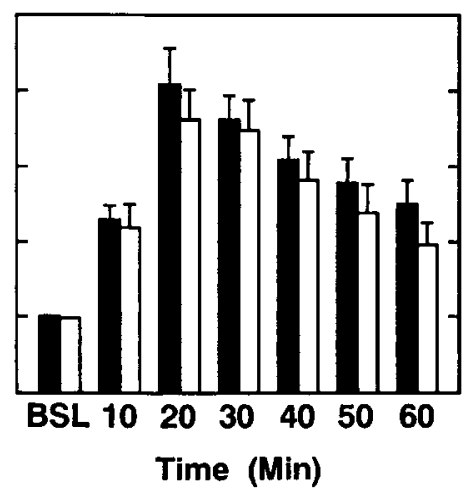

DAY 3 Post-Cocaine

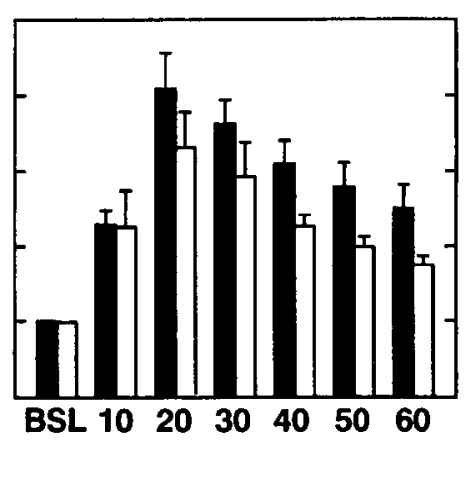

DAY 7 Post-Cocaine

Figure 2. Dialysate DA concentrations after cocaine challenge. Effects of repeated-cocaine $(30 \mathrm{mg} / \mathrm{kg} / \mathrm{d}$, i.p.) versus vehicle pretreatment for 10 consecutive days on DA overflow in response to cocaine challenge injections ( $10 \mathrm{mg} / \mathrm{kg}$, i.p.) administered on $D A Y 1(n=13), D A Y 3(n=12)$, or $D A Y 7(n=11)$ after termination of pretreatments. Upper panels, Absolute dialysate DA concentrations reached higher levels in repeatedcocaine- than in vehicle-treated rats. This effect was strongest on $D A Y 1$ and decreased over time in the $D A Y 3$ and $D A Y 7$ challenge groups. Lower panels, Dialysate DA concentrations expressed as percentage of basal $(B S L)$ levels. The relative increases in DA levels induced by cocaine challenge were smaller in animals that received repeated cocaine as opposed to vehicle. This attenuation in the effects of cocaine challenge injections on DA overflow was significant on $D A Y 1$. Control data represent the pooled data of all repeated-saline-treated animals. ${ }^{* *}, p<0.01 ;{ }^{*}, p<0.05$ (simple effects after ANOVA).

obtained with the higher pretreatment dose of cocaine above. The absolute rate of disappearance of extracellular DA was increased in daily-cocaine- relative to daily-saline-pretreated rats $(F=4.36 ; \mathrm{df}=6 / 108 ; p<0.001 ;$ Fig. $3 B)$. However, expressed as percentage of basal values, the rate of DA disappearance was reduced in the repeated-cocaine group and the overall response profile of extracellular DA to cocaine challenge was blunted $(F$ $=5.48 ; \mathrm{df}=6 / 108 ; p<0.001 ;$ Fig. $3 C$ ).
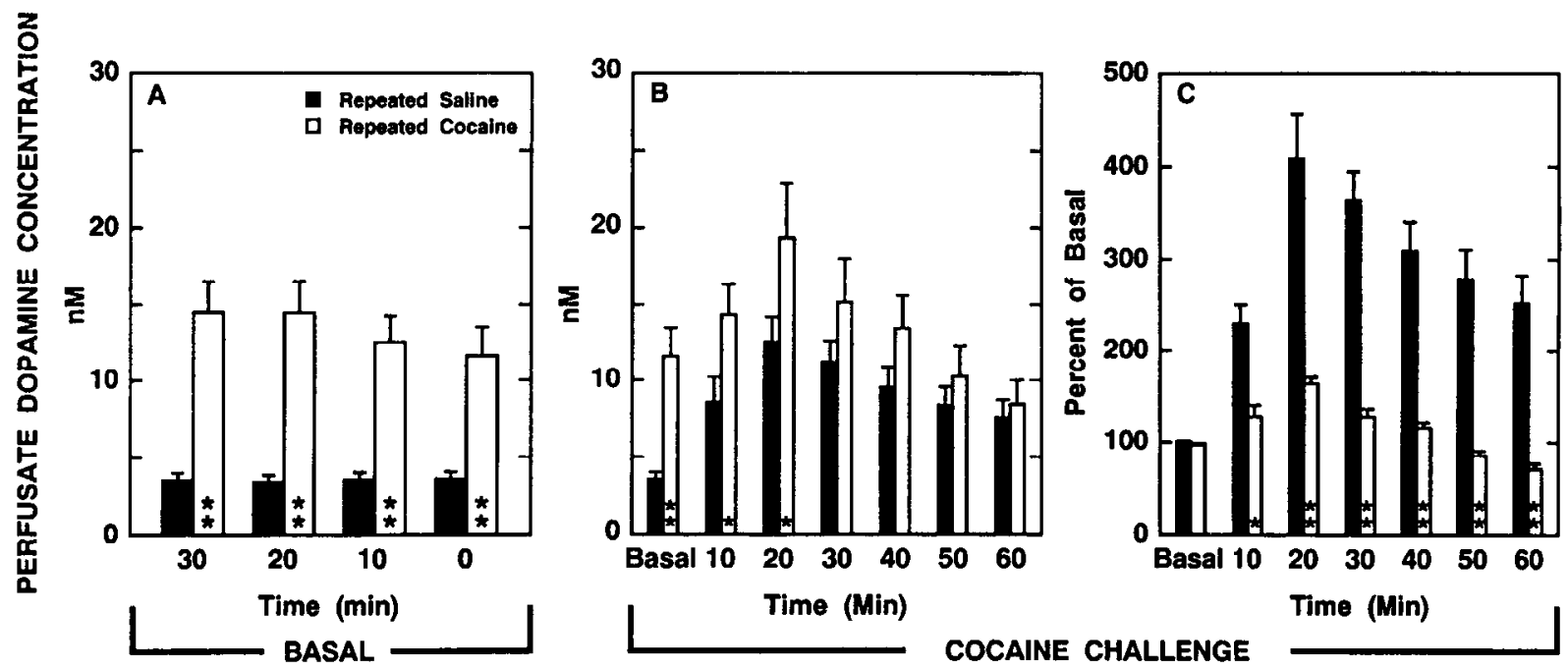

Figure 3. Effects of low-dose repeated cocaine pretreatment on extracellular DA levels. $A$, Basal DA levels in dialysate collected from the NAC. A $10 \mathrm{~d}$ repeated pretreatment period $(n=6)$ using a $10 \mathrm{mg} / \mathrm{kg}$ daily dose of cocaine produced increases in basal DA release similar to those observed with the $30 \mathrm{mg} / \mathrm{kg}$ repeated dose above. $B$ and $C$, DA levels after cocaine challenge. Absolute DA levels $(B)$ were significantly increased by repeated cocaine exposure. The same pretreatment considerably attenuated relative increases in DA overflow $(C)$ over basal levels. Chronic-cocaine effects are compared to the same repeated-vehicle group $(n=14)$ as in Figure 2 above. ${ }^{* *}, p<0.001 ; *, p<0.01$ (simple effects after ANOVA). 


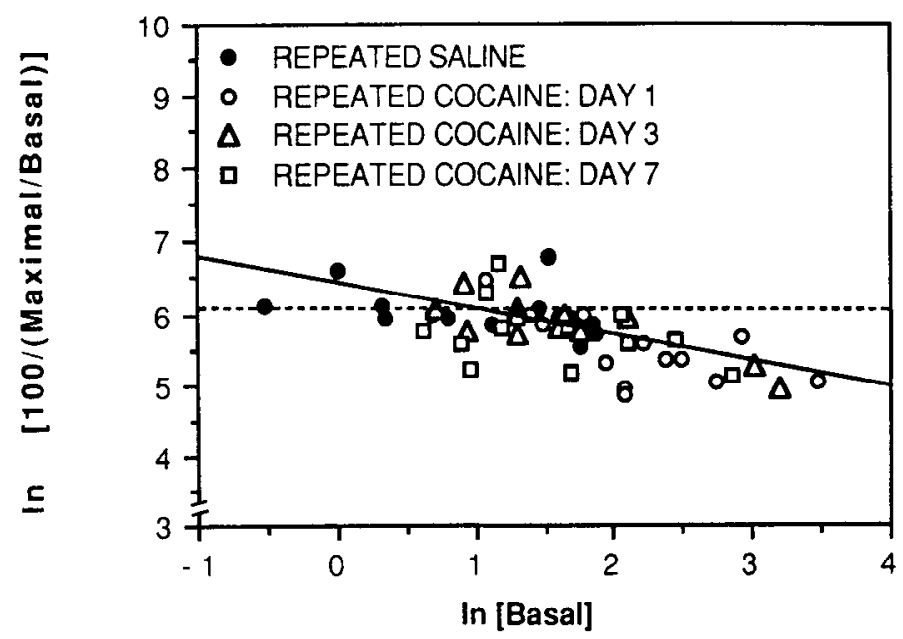

Figure 4. Dependence of maximal DA levels after cocaine challenge on basal DA concentrations: double logarithmic plot of the maximal percentage of basal DA concentrations observed between 10 and 30 min after cocaine challenge injections plotted as a function of basal DA levels. Increases in DA levels produced by cocaine challenge were inversely related to basal DA concentrations. The figure illustrates that the magnitude of the elevation in extracellular DA after challenge injections becomes progressively smaller as basal DA levels increase.

Relationship between basal DA overflow and maximal DA levels after cocaine challenge. The relationship between basal levels and the maximal increase in extracellular DA produced by cocaine challenge was further explored by expressing cocaine challenge effects as a function of basal DA concentrations, using the ln-transformed data of all animals treated with the $30 \mathrm{mg} /$ $\mathrm{kg}$ repeated-cocaine dose or vehicle. The negative correlation in the resulting plot indicated that the magnitude of the increases in DA overflow, expressed as In percentage of basal values, was inversely related to basal DA levels (Fig. 4). This observation suggests that although the absolute extracellular DA concentrations associated with cocaine challenge injections continue to increase with increasing basal levels, the differences between basal and maximal challenge-induced DA overflow become progressively smaller.

To test this hypothesis and to determine whether the relationship between basal and cocaine challenge-induced increases in extracellular DA differs as a function of repeated-cocaine versus saline treatment, In-transformed dialysate concentrations were subjected to linear regression analyses. For each animal, the $\ln$ basal concentration immediately prior to the cocaine challenge injection was compared to the highest $\ln$ DA concentration obtained between 10 and 30 min following administration of the drug. The slopes of the regression lines were subsequently tested for significant negative deviations from 1.0 as well as for differences among daily-cocaine and -saline treatment groups. Regression analyses confirmed a significant relationship between maximal and basal DA levels in the repeated-saline$(F=78.89 ; \mathrm{df}=1 / 12 ; p<0.001)$ and all repeated-cocainepretreated rats (day $1: F=25.73$; df $=1 / 11 ; p<0.01$; day 3 : $F=11.3 ; \mathrm{df}=1 / 10 ; p<0.005 ;$ day $7: F=15.96 ; \mathrm{df}=1 / 11 ;$ $p<0.002)$. The slopes $( \pm \mathrm{SEM})$ of all regression lines were smaller than 1.0 [repeated saline: $0.66( \pm 0.08)$; repeated cocaine: day $1,0.56( \pm 0.17)$; day $3,0.55( \pm 0.11)$; day $7,0.76$ $( \pm 0.19)]$ and thus were suggestive of hyperbolic, nonlinear relationships between basal and maximal DA levels in the untransformed data.
Confidence intervals of the slopes did not include 1.0 at the $99 \%$ (repeated saline, repeated cocaine: day 3 ) or $95 \%$ (repeated cocaine: day 1) level, except in the day 7 repeated-cocaine group, where only a marginal difference $(90 \%$ confidence interval) from 1.0 was obtained, confirming that with increasing basal concentrations, cocaine challenge produced proportionally smaller additional increases in extracellular DA levels. No statistical differences among the slopes were noted, which suggests that this finding reflects a general relationship characterizing the dopaminergic responsivity to cocaine challenge that is not changed by repeated cocaine pretreatments. However, repeated cocaine administration produced a shift in the distribution of the data toward higher basal levels and -in accordance with the observed dependence on basal DA concentrations-smaller relative increases in DA overflow after cocaine challenge (Fig. 5). The distributions converged again $7 \mathrm{~d}$ after repeated cocaine treatments were discontinued (i.e., when basal levels returned to control values).

\section{Discussion}

The experimental results confirm that repeated administration of cocaine can produce marked adaptive changes in mesocorticolimbic DA function that, at the synaptic level, result in enhanced basal DA release in the NAC and altered responsivity to cocaine challenge.

Basal extracellular DA levels were elevated most strongly on day 1 post-cocaine, when DA overflow was increased to approximately $300 \%$ of basal values in daily-saline-treated rats. Although DA release is increased during halothane anesthesia (Ståhle et al., 1990), this effect does not appear to be involved in the observed differences. Halothane-induced DA release does not resemble the pattern of release produced by either amphetamine (Zetterström et al., 1983) or cocaine (Hurd and Ungerstedt, 1989a), does not modify apomorphine-induced inhibition of DA release (Ståhle et al., 1990), and, at least after brief exposure, does not alter DA synthesis (Andén et al., 1974). Thus, this anesthetic does not seem to interact with synaptic functions that are altered by chronic cocaine administration. The validity of the results is further supported by previous observations in awake rats where daily access to intravenous cocaine produced a $300 \%$ increase in basal DA overflow in the NAC similar to that reported here (Weiss et al., 1992a,b).

It also appears unlikely that the elevation in basal DA levels can be attributed to residual brain cocaine concentrations due to sequestration and subsequent slow release from adipose tissue. Residual brain ${ }^{3} \mathrm{H}$-cocaine levels of 0.04 and $0.02 \mu \mathrm{g} / \mathrm{gm}$, respectively, have been detected in rats 2 and $4 \mathrm{~d}$ after $21 \mathrm{~d}$ of chronic treatment (Nayak et al., 1976). However, the amount of residual cocaine in brain tissue (which constituted only about $0.7-1.3 \%$ of the peak concentration induced by a $20 \mathrm{mg} / \mathrm{kg}$ cocaine dose; Nayak et al., 1976) appears insufficient to exert an appreciable effect on basal extracellular DA levels. More importantly, significant residual levels of cocaine in brain or adipose tissue of rats could not be detected when measured 24 $\mathrm{hr}$ after $10 \mathrm{~d}$ of repeated cocaine treatment, suggesting that a 10 $\mathrm{d}$ administration regimen as in the present study is not sufficient to produce substantial sequestration of cocaine (Pan et al., 1991).

The increase in basal extracellular DA levels persisted for 3 $\mathrm{d}$ but was no longer evident $7 \mathrm{~d}$ post-cocaine, a finding that is consistent with the duration of changes in stimulated DA release and DA uptake produced by repeated cocaine ( $\mathrm{Ng}$ et al., 1991), and the time course of daily cocaine-induced or $d$-amphet- 

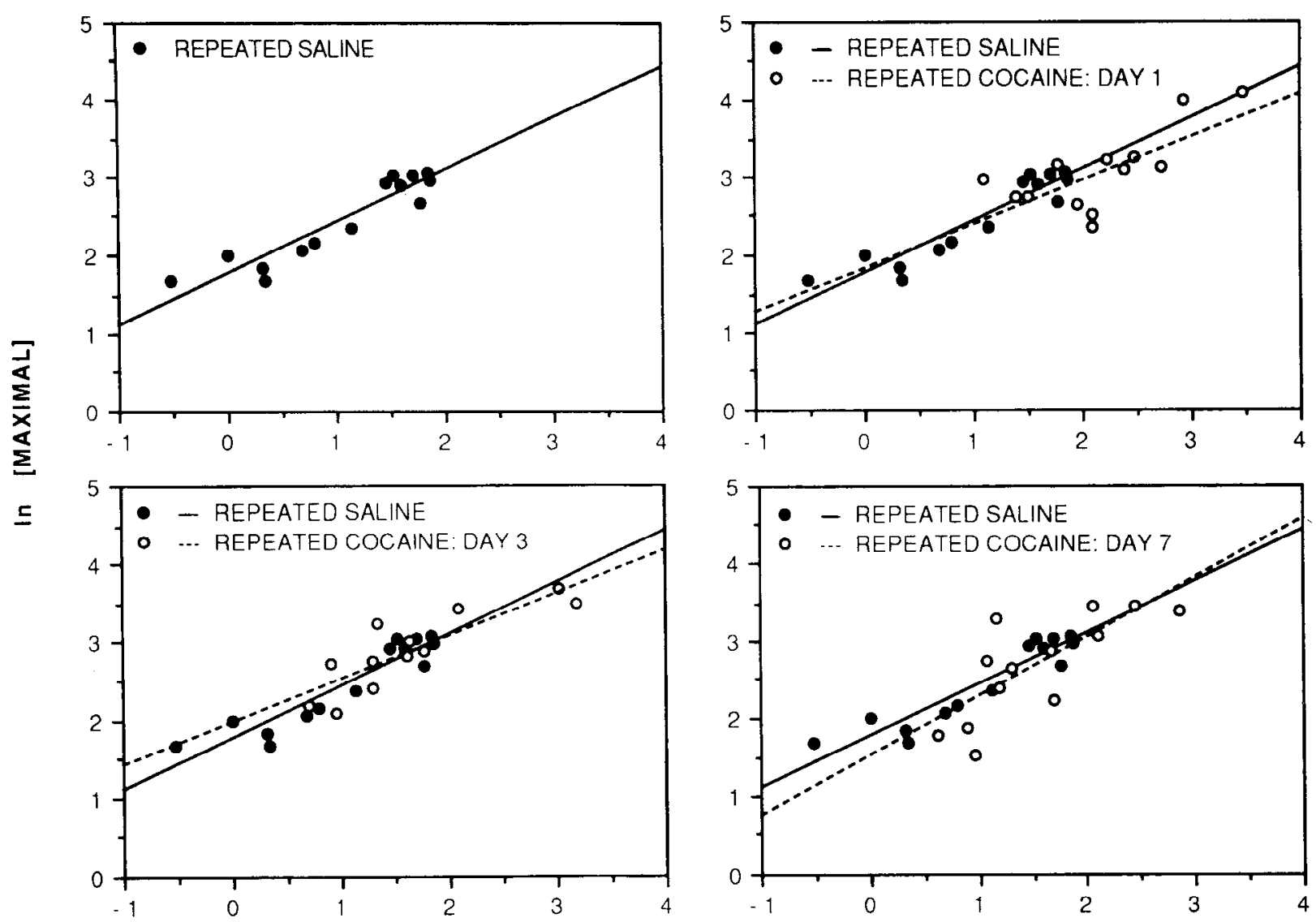

In [BASAL]

Figure 5. Relationship between basal DA levels and cocaine challenge effects in individual treatment groups. Double logarithmic plot of basal versus maximal extracellular DA levels in the NAC after cocaine challenge. The broken line represents the mean maximal DA concentration in repeated-saline control rats. A significant dependence between basal and maximal DA levels was apparent in all rats irrespective of pretreatment or length of the post-cocaine interval. The slopes of the regression lines were all less than 1.0, indicating that cocaine challenge injections produced a proportionally smaller increase in extracellular DA in animals exhibiting high basal DA overflow than in rats with lower basal DA levels. No differences among the slopes of individual treatment groups were observed; thus, repeated cocaine administration did not alter the nature of the dependence between basal and maximal DA overflow. However, repeated cocaine pretreatment was associated with higher basal DA levels and, consequently, proportionally smaller drug challenge-induced increases in DA overflow. This pattern was reversed again with increasing time after discontinuation of repeated cocaine pretreatment. For ease of comparison, the data of the pooled repeated-saline control groups (upper left panel) are represented together with the data of each of the repeated-cocaine groups.

amine-induced somatodendritic DA autoreceptor subsensitivity (White and Wang, 1984; Ackerman and White, 1990). In the latter electrophysiological work, repeated cocaine administration over 2 weeks induced a subsensitivity of A10 somatodendritic, impulse-regulating DA autoreceptors-associated with increases in both firing rate and the number of spontaneously active A10 DA neurons-that persisted for $4 \mathrm{~d}$ but not 8 $\mathrm{d}$ after termination of repeated cocaine treatment (Henry et al., 1989; Ackerman and White, 1990). The similarity in the time course of these and the present neurochemical changes suggests that the enhanced basal DA release following repeated cocaine may be a direct result of increased mesocorticolimbic DA neuronal activity due to impaired autoinhibitory control by subsensitive A10 somatodendritic DA autoreceptors.

The time course of the modifications in DA function elicited by repeated cocaine administration in this as well as other electrophysiological and neurochemical work (Ackerman and White, 1990; Ng et al., 1991; Parsons et al., 1991) suggests also that the persistence of the adaptive cellular changes that enhance basal mesocorticolimbic DA activity is limited. Moreover, the elevation in basal DA release during the early post-cocaine stage may be followed by a deficiency in synaptic DA at a later stage. In support of this possibility, basal DA levels in the NAC were recently shown to be decreased by day 14 following the same $10 \mathrm{~d}$ pretreatment duration as in the present work, and as early as $7 \mathrm{~d}$ following a longer $18 \mathrm{~d}$ daily cocaine treatment regimen (Parsons et al., 1991; Robertson et al., 1991). Similarly, while increased levels of basal extracellular DA were noted in the NAC of cocaine self-administering rats $24 \mathrm{hr}$ following a 2 week period of daily limited access ( $3 \mathrm{hr}$ ) to cocaine, the same animals showed a significant deficiency in basal DA release as early as 4-6 hr after 8-15 hr of continuous intravenous cocaine self-administration (Weiss et al., 1992a,b). Together, these findings imply that the duration of the initial adaptive stage characterized by increased basal DA activity depends on the duration and dosage of the chronic cocaine treatments, and that the onset of the second, "deficiency" stage is accelerated by higher cocaine doses and longer (or continuous) treatment regimens.

Extracellular DA levels in response to cocaine challenge were also significantly higher in rats repeatedly treated with cocaine than in daily saline-treated controls. This observation is in agreement with previous findings showing an increase in cocaine 
challenge-induced extracellular DA levels in the NAC after daily pretreatments (Kalivas et al., 1988; Kalivas and Duffy, 1990; Pettit et al., 1990), increased electrically stimulated release $(\mathrm{Ng}$ et al., 1991), and potentiation of $d$-amphetamine-induced and $\mathrm{K}^{+}$-induced release of DA from striatal slices ( $\mathrm{Yi}$ and Johnson, 1991). The time course of the augmentation in the challengeinduced DA overflow paralleled the increases in basal release: differences between previously drug-naive and daily-cocainctreated animals were most prominent on day 1 but were no longer apparent on day 7 post-cocaine. It would seem, therefore, that the higher levels of extracellular DA induced by cocaine challenge in rats with prior cocaine exposure are the result of increased availability of synaptic DA due to enhanced basal release. Pettit et al. (1990) have demonstrated that brain cocaine levels in response to a cocaine challenge injection are increased in chronically pretreated animals, an effect that has been attributed to enhanced or accelerated absorption of the drug (Pan et al., 1991). Thus, the higher extracellular DA concentrations after cocaine challenge may be a consequence of both an increase in brain cocaine concentrations and enhanced basal release, but do not appear to involve a sensitization to the DA reuptake blocking properties of cocaine.

Although cocaine-experienced animals showed higher absolute extracellular DA levels, the relative (percentage of basal) increase in DA overflow after challenge injections was significantly reduced by the daily cocaine pretreatment, particularly on day 1 (i.e., when basal DA levels were most strongly elevated). Indeed, in view of the possibility that increases in brain cocaine levels occur with repeated treatment (Pettit et al., 1990), the true efficacy of cocaine to stimulate extracellular DA may be even smaller than suggested by the data. The proportionally reduced efficacy of cocaine challenge may involve several adaptive cellular or metabolic processes including pharmacokinetic factors, increased competition for DA uptake sites, or a "ceiling effect" due to DA depletion, although the precise mechanism remains unclear. Partial depletion of intraneuronal DA pools may restrict additional increases in extracellular DA by cocaine while permitting increases in basal DA release. However, previous work has failed to demonstrate a reduction of total tissue DA content in the NAC after repeated cocaine treatments (Kleven et al., 1988; Hurd et al., 1989), and increases in the dose or frequency of cocaine injections (Pettit and Justice, 1991) or administration of $d$-amphetamine (Hurd and Ungerstedt, 1989b) can further elevate synaptic DA levels in previously cocaineexposed rats. Similarly, although DA synthesis is significantly reduced by repeated cocaine administration (Brock et al., 1990), electrically stimulated release of DA is increased by more than $40 \%$ ( $\mathrm{Ng}$ et al., 1991). A possible explanation for the proportionally smaller effects of cocaine challenge on extracellular DA levels may lie in the increased competition for DA transporter sites due to the substantially higher absolute synaptic DA concentrations in repeatedly cocaine-treated rats, which would favor higher DA uptake. Increased DA uptake in chronic-cocainetreated rats has been demonstrated in vivo and in vitro $(\mathrm{Ng}$ et al., 1991; Yi and Johnson, 1991). Accelerated disappearance of DA after repeated cocaine treatment suggestive of increased uptake was also evident in the present data (Fig. 2, upper panels). However, the rate of disappearance relative to basal levels was actually lower in repeated-cocaine- than saline-treated rats (Fig. 2 , lower panels). Thus, increased DA uptake may not be sufficient by itself to account for the proportionally diminished effects of cocaine in animals with prior cocaine exposure.
The 10 and $30 \mathrm{mg} / \mathrm{kg}$ daily cocaine doses produced a nearly identical pattern of effects on basal and cocaine challenge-stimulated extracellular DA levels on day 1 post-cocaine. Interestingly, a similar independence of the chronic treatment dose has been reported for the development of tolerance to the discriminative stimulus properties of cocaine (Wood and Emmett-Oglesby, 1986), and for chronic $d$-amphetamine-induced subsensitivity of somatodendritic DA autoreceptors in the ventral tegmental area (White and Wang, 1984). Thus, the immediate changes in DA function may not be sensitive to variations in repeated cocaine doses in this range, although as hypothesized above, the persistence of these changes after discontinuation of drug treatments is likely to vary as a function of dose.

Analysis of the relationship between basal and challenge-induced DA overflow indicated that the magnitude of the increase in extracellular DA that can be produced by a given dose of cocaine is inversely related to basal DA levels. Although the results provide little insight into the physiological or neurochemical bases of this relationship, this finding presumably involves the activation of autoinhibitory feedback mechanisms. The progressively smaller relative increases in extracellular DA elicited by cocaine challenge are reminiscent of a saturation curve and, consequently, may reflect receptor-mediated inhibitory effects on DA release and synthesis. Acute administration of cocaine causes a rapid, transient inhibition of DA synthesis in the NAC (Nielsen et al., 1983; Galloway, 1990). Moreover, while A10 DA neuronal activity is not completely inhibited by acute systemic administration of cocaine, the firing rate of these neurons is, nonetheless, significantly reduced (Einhorn et al., 1988). It is possible that these compensatory mechanisms are activated more rapidly or strongly in animals with higher rates of basal DA release, thereby limiting the amount of cocaineinduced accumulation of extracellular DA relative to animals with lower basal levels of synaptic DA. Since this relationship characterized the data of both drug-naive and cocaine-experienced rats, a general dependence of cocaine effects on basal DA release seems to exist whereby increasing basal concentrations are associated with increasingly smaller relative increases in DA levels. Thus, repeated exposure to cocaine appears not only to enhance basal release (Kalivas et al., 1988; Kalivas and Duffy, 1990; Ackerman and White, 1990), but also to modify the autoregulatory functions (and perhaps to activate additional adaptive cellular responses) responsible for the proportionally reduced effects of cocaine challenge.

These present findings may have several important implications with regard to the neuropharmacology of cocaine reward, behavioral activation, and the pathological side effects of chronic cocaine abuse. First, the inverse relationship between basal and cocaine-stimulated peak DA levels suggests that the responsivity of dopaminergic terminals in the NAC to pharmacological challenge by cocaine (and presumably other reuptake inhibitors) is proportionally reduced if the system is operating at a higher basal tone. Curiously, this type of negative correlation has long been a characteristic of the relationship between the rate of spontaneous behavioral activity and the rate of stimulant-induced behavioral activation (Dews, 1958). This "rate dependency" has been observed across species and behavioral paradigms. For example, locomotor activation by stimulant drugs shows rate dependency in rodents, pigeons, and humans as does operant responding (Robbins and Sahakian, 1979). Moreover, this rate dependency has been the basis of a general theory of psychostimulant action (Lyon and Robbins, 1975), and the pres- 
ent results may, in fact, provide a physiological basis for this well-documented behavioral phenomenon.

Second, it has been proposed repeatedly that an enhanced functional response of DA neurons to exogenous or endogenous agonists due to somatodendritic DA autoreceptor subsensitivity may play a key role in amphetamine psychosis and possibly paranoid psychosis in general (Schwartz et al., 1978; Antelman and Chiodo, 1981; White and Wang, 1984). The present data demonstrate that the same repeated cocaine treatment regimen that was shown to decrease somatodendritic DA autoreceptor sensitivity in other work produces a marked increase in basal release in the NAC, thus providing strong support for the possibility that increased basal DA release may play a role in the psychotic-like symptoms associated with chronic use and abuse of cocaine (Post and Kopanda, 1976; Post and Contel, 1981).

Finally, repeated cocaine administration is frequently accompanied by the emergence of reverse tolerance to the motor stimulant actions of the drug (e.g., Post and Rose, 1976; Post and Weiss, 1988). The strong elevation of absolute DA concentrations in daily-cocaine-treated rats after cocaine challenge is in agreement with previous findings (Kalivas et al., 1988; Kalivas and Duffy, 1990; Robertson et al., 1991) and provides further support for the hypothesis that increased extracellular DA levels in the NAC provide a neuropharmacological basis for the increased motoric responses in sensitized animals, particularly those that develop during the course of repeated or chronic cocaine treatments (Roy et al., 1978; Robertson et al., 1991).

In contrast to the progressive enhancement of motor behaviors by repeated cocaine administration, however, such treatments can reduce the subjective-euphorigenic effects (Fishman et al., 1985) and induce apparent tolerance to the discriminative stimulus and reinforcing properties of cocaine (Wood and Emmett-Oglesby, 1986; Emmett-Oglesby and Lane, 1992). Previous exposure to cocaine raises the threshold dose for maintenance of cocaine self-administration and increases response rates for intravenous cocaine reward (Emmett-Oglesby and Lane, 1992). Similarly, cocaine self-administering animals increase their drug intake over a $10 \mathrm{~d}$ acquisition period by more than $200 \%$, even when learning effects are partialled out (F. Weiss and G. F. Koob, unpublished observations). The present observations suggest that the considerably reduced efficacy of cocaine to elevate extracellular DA over basal levels after repeated exposure may play an important role in these behavioral reports of tolerance. It is interesting to speculate that the behavioral signs of tolerance after repeated cocaine treatment above may reflect the operation of rate dependency effects in DA-mediated reward such that the diminished rate of change in extracellular DA stimulated by given dose of cocaine is also associated with a decrease in the "reward magnitude" of cocaine. However, this interpretation rests on the assumption that behavioral activation (i.e., sensitization of motor behaviors) increases with increased absolute extracellular DA concentrations while the reinforcing effects of cocaine depend solely on the degree of change in DA over steady-state basal levels. Clearly, additional research to elucidate the changes in DA function responsible for tolerance to the rewarding effects of cocaine is necessary.

In summary, the present data suggest (1) that repeated cocaine exposure produces a sustained tonic increase in basal DA release from the NAC that is possibly mediated by subsensitive somatodendritic DA autoreceptors, resulting in a disinhibition of mesocorticolimbic DA neurons and, consequently, increased extracellular DA levels; (2) that the augmentation in the absolute amounts of extracellular DA after cocaine challenge in repeatedcocaine-treated rats is related to this overall activation and does not represent a sensitization to the DA reuptake blocking actions of cocaine; and (3) that the reduction in the efficacy of cocaine to increase extracellular DA levels when expressed in terms of percentage of basal levels may reflect some form of tolerance to the pharmacological effects of cocaine.

\section{References}

Ackerman JM, White FJ (1990) Al0 somatodendritic dopamine autoreceptor sensitivity following withdrawal from repeated cocaine treatment. Neurosci Lett 117:181-187.

Andén N-E, Magnusson T, Stock G (1974) Effects of anaesthetic agents on the synthesis and disappearance of brain dopamine normally and after haloperidol. Naunyn Schmiedebergs Arch Pharmacol 283:409418 .

Antelman SM, Chiodo LA (1981) Dopamine autoreceptor subsensitivity: a mechanism common to the treatment of depression and the induction of amphetamine psychosis. Biol Psychiatry 8:717-727.

Beitner-Johnson D, Nestler EJ (1991) Morphine and cocaine exert common chronic actions on tyrosine hydroxylase in dopaminergic brain reward regions. J Neurochem 57:344-347.

Brock JW, Ng JP, Justice JB Jr (1990) Effect of chronic cocaine on dopamine synthesis in the nucleus accumbens as determined by microdialysis perfusion with NSD-1015. Neurosci Lett 117:234-239.

DeWit H, Wise RA (1977) Blockade of cocaine reinforcement in rats with the dopamine receptor blocker pimozide, but not with the noradrenergic blockers phentolamine and phenoxybenzamine. Can J Psychol 31:195-203.

Dews PB (1958) Studies on behavior. IV. Stimulant actions of methamphetamine. J Pharmacol Exp Ther 122:137-147.

Dwoskin LP, Peris J, Yasuda RP, Philpott K, Zahniser NR (1988) Repeated cocaine administration results in supersensitivity of striatal D-2 dopamine autoreceptors to pergolide. Life Sci 42:255-262.

Einhorn LC, Johansen PA, White FJ (1988) Electrophysiological effects of cocaine in the mesoaccumbens dopamine system: studies in the ventral tegmental area. J Neurosci 8:100-112.

Emmett-Oglesby MW, Lane JD (1992) Tolerance to the reinforcing effects of cocaine. Behav Pharmacol, in press.

Fishman MW, Schuster CR, Javaid J, Hatano Y, Davis J (1985) Acute tolerance to the cardiovascular and subjective effects of cocaine. $J$ Pharmacol Exp Ther 235:677-682.

Galloway MP (1990) Regulation of dopamine and serotonin synthesis by acute administration of cocaine. Synapse 6:63-72.

Goeders NE, Kuhar MJ (1987) Chronic cocaine administration induces opposite changes in dopamine receptors in the striatum and nucleus accumbens. Alcohol Drug Res 7:207-216.

Henry DJ, Greene MA, White FJ (1989) Electrophysiological effects of cocainc in the mesoaccumbens dopamine system: repeated administration. J Pharmacol Exp Ther 251:833-839.

Horger BA, Shelton K, Schenk S (1990) Preexposure sensitizes rats to the rewarding effects of cocaine. Pharmacol Biochem Behav 37: $707-711$.

Hurd YL, Ungerstedt U (1989a) In vivo neurochemical profile of dopamine reuptake inhibitors and releasers in rat caudate-putamen. Eur J Pharmacol 166:251-260.

Hurd YL, Ungerstedt U (1989b) Influence of a carrier transport process on in vivo release and metabolism of dopamine: dependence on extracellular $\mathrm{Na}^{+}$. Life Sci 45:283-293.

Hurd YL, Weiss F, Koob GF, Andén N-E, Ungerstedt U (1989) Reinforcing effects of cocaine are dissociated from dopamine release in rat nucleus accumbens: an in vivo microdialysis study. Brain Res 489: 199-203.

Kalivas PW, Duffy P (1990) The effect of acute and daily cocaine treatment on extracellular dopamine in the nucleus accumbens. Synapse 5:48-58.

Kalivas PW, Duffy P, DuMars LA, Skinner C (1988) Behavioral and neurochemical effects of acute and daily cocaine administration in rats. J Pharmacol Exp Ther 245:485-492.

Kelly P, Seviour P, Iversen S (1976) Selective 6-OHDA induced destruction of mesolimbic dopamine neurons: abolition of psychostimulant induced locomotor activity in rats. Eur J Pharmacol 40:4556. 
Kleven MS, Woolverton WL, Seiden LS (1988) Lack of long-term monoamine depletions following repeated or continuous exposure to cocaine. Brain Res Bull 21:233-237.

Kokkinidis L, McCarter BD (1990) Postcocaine depression and sensitization of brain stimulation reward: analysis of reinforcement and performance effects. Pharmacol Biochem Behav 36:463-471.

Koob GF, Vaccarino FJ, Amalric M, Bloom FE (1987) Positive reinforcement properties of drugs: search for neural substrates. In: Brain reward systems and abuse (Engel J, Oreland L, eds), pp 35-50. New York: Raven.

Lett BT (1989) Repeated exposures intensify rather than diminish the rewarding effects of amphetamine, morphine, and cocaine. Psychopharmacology 98:357-362.

Lyon M, Robbins TW (1975) The action of central nervous system stimulant drugs: a general theory concerning amphetamine effects. In: Current developments in psychopharmacology (Essman WB, Valzelli L, eds), pp 80-163. New York: Spectrum.

Markou A, Koob GF (1991) Post cocaine anhedonia. An animal model of cocaine withdrawal. Neuropharmacology 4:17-26.

Nayak PK, Misra AL, Mul SJ (1976) Physiological disposition and biotransformation of $\left[{ }^{3} \mathrm{H}\right]$ cocaine in acutely and chronically treated rats. J Pharmacol Exp Ther 196:556-569.

$\mathrm{Ng}$ JP, Hubert GW, Justice JB Jr (1991) Increased stimulated release and uptake of dopamine in the nucleus accumbens after repeated cocaine administration as measured by in vivo voltammetry. $J$ Neurochem 56:1485-1492.

Nielsen JA, Chapin DS, Moore KE (1983) Differential effects of $d$ amphetamine, beta-phenylethylamine, cocaine and methylphenidate on the rate of dopamine synthesis in terminals of nigrostriatal and mesolimbic neurons and on the efflux of dopamine metabolites into cerebroventricular perfusates of rats. Life Sci 33:1899-1907.

Pan H-T, Menacherry S, Justice JB Jr (1991) Differences in the pharmacokinetics of cocaine in naive and cocaine-experienced rats. J Neurochem 56:1299-1306.

Parsons LH, Smith AD, Justice JB Jr (1991) Basal extracellular dopamine is decreased in the rat nucleus accumbens during abstinence from chronic cocaine. Synapse 9:60-65.

Paxinos G, Watson C (1986) The rat brain in stereotaxic coordinates. San Diego: Academic.

Pettit HO, Justice JB Jr (1991) Effect of dose on cocaine self-administration behavior and dopamine levels in the nucleus accumbens. Brain Res 539:94-102.

Pettit HO, Pan HT, Parsons LH, Justice JB Jr (1990) Extracellular concentrations of cocaine and dopamine are enhanced during chronic cocaine administration. J Neurochem 55:798-804.

Post RM, Contel NR (1981) Cocaine-induced behavioral sensitization: a model for recurrent manic illness. In: Biological psychiatry (Perris C, Struwe G, Jansson B, eds), pp 746-749. New York: Elsevier.

Post RM, Kopanda RT (1976) Cocaine, kindling and psychosis. Am J Psychiatry 133:627-634.

Post RM, Rose H (1976) Increasing effects of repetitive cocaine ad ministration in the rat. Nature 260:731-732.
Post RM, Weiss SRB (1988) Psychomotor stimulant vs. local anesthetic effects of cocaine: role of behavioral sensitization and kindling. Natl Inst Drug Abuse Res Monogr Ser 88:217-238.

Robbins TW, Sahakian BJ (1979) "Paradoxical" effects of psychomotor stimulant drugs in hyperactive children from the standpoin of behavioural pharmacology. Neuropharmacology 18:931-950.

Roberts D, Koob GF (1982) Disruption of cocaine self-administration following 6-hydroxydopamine lesions of the ventral tegmental area in rats. Pharmacol Biochem Behav 17:901-904.

Roberts D, Corcoran ME, Fibiger HC (1977) On the role of ascending catecholaminergic systems in intravenous self-administration of cocaine. Pharmacol Biochem Behav 6:615-620.

Robertson MW, Leslie CA, Bennet JP Jr (1991) Apparent synaptic deficiency induced by withdrawal from chronic cocaine treatment. Brain Res 538:337-339.

Roy SN, Bhattacharyya AK, Pradhan S, Pradhan SN (1978) Behavioural and neurochemical effects of repeated administration. Neuropharmacology 17:559-564.

Schwartz JC, Costentin J, Martres MP, Protais P, Baudry M (1978) Modulation of receptor mechanisms in the CNS: hyper- and hyposensitivity to catecholamines. Neuropharmacology 17:665-685.

Ståhle L, Collin A-K, Ungerstedt U (1990) Effects of halothane anesthesia on extracellular levels of dopamine, dihydroxyphenylacetic acid, homovanillic acid and 5-hydroxyindoleacetic acid in rat striatum: a microdialysis study. Naunyn Schmiedebergs Arch Pharmacol 342:136-140.

Taylor D, Ho BT (1977) Neurochemical effects of cocaine following acute and repeated injection. J Neurosci Res 3:95-101.

Trulson ME, Ulissey MJ (1987) Chronic cocaine administration decreases dopamine synthesis rate. Brain Res Bull 19:35-38.

Weiss F, Hurd YL, Ungerstedt U, Markou A, Plotsky PM, Koob GF (1992a) Neurochemical correlates of cocaine and ethanol self-administration. Ann NY Acad Sci 654:220-241.

Weiss F, Markou A, Lorang MT, Koob GF (1992b) Basal extracellular dopamine levels in the nucleus accumbens are decreased during cocaine withdrawal after unlimited-access self-administration. Brain Res, in press.

White FJ, Wang RY (1984) Electrophysiological evidence for A10 dopamine autoreceptor subsensitivity following chronic $d$-amphetamine treatment. Brain Res 309:283-292.

Wood DM, Emmett-Oglesby MW (1986) Characteristics of tolerance, recovery from tolerance and cross-tolerance for cocaine used as a discriminative stimulus. J Pharmacol Exp Ther 237:120-125.

Yi S-J, Johnson KJ (1990) Chronic cocaine treatment impairs the regulation of synaptosomal ${ }^{3} \mathrm{H}-\mathrm{DA}$ release by $\mathrm{D}_{2}$ autoreceptors. Pharmacol Biochem Behav 36:457-461.

Yi S-Y, Johnson KJ (1991) Effects of acute and chronic administration of cocaine on striatal uptake, compartmentalization and release of $\left[{ }^{3} \mathrm{H}\right]$ dopamine. Neuropharmacology 29:475-486.

Zetterström T, Sharp T, Marsden CA, Ungerstedt U (1983) In vivo measurement of dopamine and its metabolites by intracercbral dialysis: changes after $d$-amphetamine. J Neurochem 41:1769-1773. 